\title{
Model Tests on the Penetration Resistance of Bucket Foundations for Offshore Wind Turbines in Sand
}

\author{
Hongyan Ding ${ }^{1,2,3}$, Yanjian Peng ${ }^{3}$, Puyang Zhang ${ }^{1,3, *}$, Hanbo Zhai ${ }^{3}$ and Nan Jia ${ }^{3,4}$ \\ 1 State Key Laboratory of Hydraulic Engineering Simulation and Safety, Tianjin University, \\ Tianjin 300072, China; dhy_td@163.com \\ 2 Key Laboratory of Coast Civil Structure Safety, Ministry of Education, Tianjin University, \\ Tianjin 300072, China \\ 3 School of Civil Engineering, Tianjin University, Tianjin 300072, China; noheart476@163.com (Y.P.); \\ zhaihanbo@tju.edu.cn (H.Z.); 13902135312@163.com (N.J.) \\ 4 Tianjin Research Institute for Water Transport Engineering, Tianjin 300456, China \\ * Correspondence: zpy@tju.edu.cn
}

Received: 19 April 2020; Accepted: 20 May 2020; Published: 22 May 2020

\begin{abstract}
Driven by the rapid development of offshore wind farms, bucket foundations have come to constitute a very promising form of foundation for offshore wind turbines, mainly owing to their efficient construction. However, the penetration resistance of the suction penetration of a bucket foundation, when calculated inaccurately, may lead to installation failure of the foundation. In this study, model tests were performed on the suction penetration of a mono-bucket mono-compartment foundation and a mono-bucket multi-compartment foundation in saturated fine marine sand, aiming to compare their penetration resistances and critical suctions, and the development of a soil plug in the two models was analyzed. The results will provide a design reference for the penetration construction of bucket foundations for offshore wind turbines.
\end{abstract}

Keywords: composite bucket foundation; penetration resistance; critical suction; bulkhead

\section{Introduction}

The foundations for offshore wind turbines include mono-piles, jacket piles, bucket foundations, and floating foundations [1-4]. Among them, bucket foundations have been used extensively in wind farms worldwide owing to their apparent advantages, such as convenient installation, low construction cost, and high recyclability. In 1994, Europipe 16/11-E offshore platform was successfully installed using a bucket foundation for the first time on a jacket platform in Norway [5]. In 2002, the first $3 \mathrm{MW}$ wind turbine prototype with a bucket foundation, $12 \mathrm{~m}$ in diameter and $6 \mathrm{~m}$ in height, was erected in the test field of the Frederikshavn wind farm in Denmark [6]. Three years later, another $6 \mathrm{MW}$ wind turbine prototype with a bucket foundation was mounted again in Denmark [7]. In the same year, in Germany, a $6 \mathrm{MW}$ offshore wind turbine was designed with a suction bucket foundation $[7,8]$. The whole structure was made of steel and designed with bulkheads at the top of the head cover, making it possible to increase weight through filling. The bucket wall at the bottom was used for suction penetration. In 2010, researchers at Tianjin University [9-13] developed a novel foundation for offshore wind turbines, i.e., the large-scale composite bucket foundation based on the traditional bucket foundations. Next, the test prototype was prepared, and construction completed in the sea area near Qidong, Jiangsu Province, followed by one-step installation. By 2019, the composite bucket foundation was successfully applied to the 3.3 MW and 6.45 MW offshore wind turbines of the Jiangsu Dafeng offshore wind farm [14]. Figure 1 shows the transportation of the CBF. 


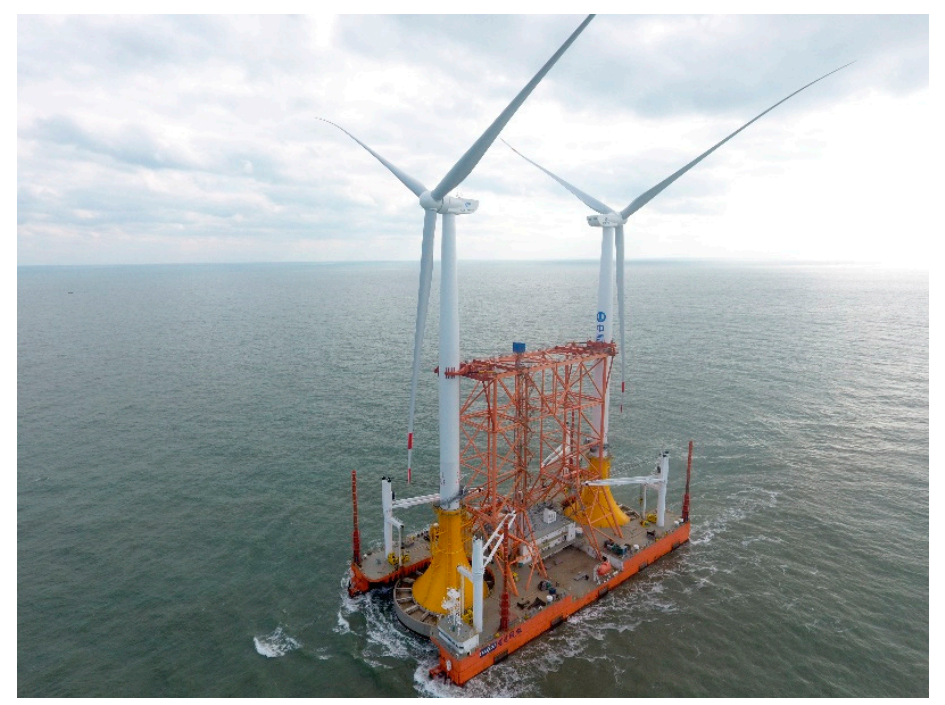

Figure 1. Composite bucket foundation for offshore wind turbines (photo was taken by the author).

Suction penetration is an important process during the installation of a bucket foundation, and it is driven by the difference pressure inside and outside the bucket $[15,16]$. The water and air in the bucket are pumped out using a vacuum pump to reduce the internal pressure to negative, thus creating a pressure difference between the inside and outside. When the pressure difference exceeds the penetration resistance, the foundation is slowly pressed into the sand. After installation, the penetration position of the foundation must meet predetermined requirements, such as its bearing capacity should reach the design value $[17,18]$. In the penetration process, soil plug and seepage failure are the main causes of installation failure. When the suction during construction is too large, the bucket experiences soil plug, or even seepage failure, inside; when it is insufficient, the foundation fails to penetrate $[19,20]$. For this reason, reasonable control of suction application has always been a core issue in this field, and the accurate prediction of penetration resistance is critical for the success of bucket foundations. In marine sand, the critical suction is the maximum suction during construction, beyond which it is susceptible to seepage failure. Existing studies mainly focus on the critical suction of the mono-compartment bucket foundation [21-25], but rarely pay attention to that of the multi-compartment bucket foundation. In fact, due to the use of inner skirt plates and bulkheads in the bucket, the seepage field of sand during penetration is different in the case of the multi-compartment bucket foundation, and the position where sand experiences initial seepage failure is also unclear. Thus, based on the research on the penetration of the composite bucket foundation [26-30], this study further compared the penetration resistance of the mono-compartment bucket foundation and the multi-compartment bucket foundation in sand. In addition, a formula was proposed for calculating the maximum critical suction of the multi-compartment bucket foundation during penetration into sand, thus offering some reference for practical engineering.

\section{Model Test}

\subsection{Test Model and Test Procedures}

The test used two models, i.e., mono-compartment bucket foundation (Model 1) and multicompartment bucket foundation (Model 2). They are wide-shallow foundations, with the aspect ratio of 0.4 , and their dimensions are listed in Table 1. The scale of the test model to the prototype is 1:100.

The test models used a steel bucket wall and a plexiglass lid connected to flanges to guarantee the sealing performance of foundations in the penetration process. In the case of the mono-compartment bucket foundation, the top lid is cut with two openings, one used for connecting to the vacuum pump and the other for connecting to the negative-pressure sensor, as shown in Figure 2a. The multi-compartment 
bucket foundation is divided into seven compartments by inner skirt plates and bulkheads, as shown in Figure 2c. The lid of each compartment also has two connection holes, one used for connecting to the vacuum pump and the other for connecting to the negative-pressure sensor. In the picture, $t$ and $t_{1}$ refer to the thickness of the bucket skirt and the bulkhead, $t_{2}$ refers to the thickness of the top lid of the model, $D_{\text {so }}$ and $D_{\text {mo }}$ refer to width of the side compartments and the central compartment respectively. The suction of each compartment can be independently controlled to level the foundation.

Table 1. Dimensions of the test model.

\begin{tabular}{|c|c|c|c|c|c|c|c|c|}
\hline Model & $\begin{array}{l}\text { Diameter } \\
(\mathrm{m})\end{array}$ & $\begin{array}{c}\text { Middle } \\
\text { Compartment } \\
\text { Diameter }(\mathrm{m})\end{array}$ & $\begin{array}{l}\text { Skirt Plate } \\
\text { Thickness } \\
\text { (mm) }\end{array}$ & $\begin{array}{c}\text { Bulkhead } \\
\text { Thickness } \\
(\mathrm{mm})\end{array}$ & $\begin{array}{c}\text { Head Cover } \\
\text { Thickness }(\mathrm{mm})\end{array}$ & $\begin{array}{c}\text { Bucket Skirt } \\
\text { Height (m) }\end{array}$ & $\begin{array}{l}\text { Total } \\
\text { Height } \\
\text { (m) }\end{array}$ & $\begin{array}{c}\text { Total } \\
\text { Weight } \\
\text { (kg) }\end{array}$ \\
\hline Model 1 & 0.3 & - & 1 & - & 10 & 0.12 & 0.13 & 3.265 \\
\hline Model 2 & 0.3 & 0.15 & 1 & 1 & 10 & 0.12 & 0.13 & 5.015 \\
\hline
\end{tabular}

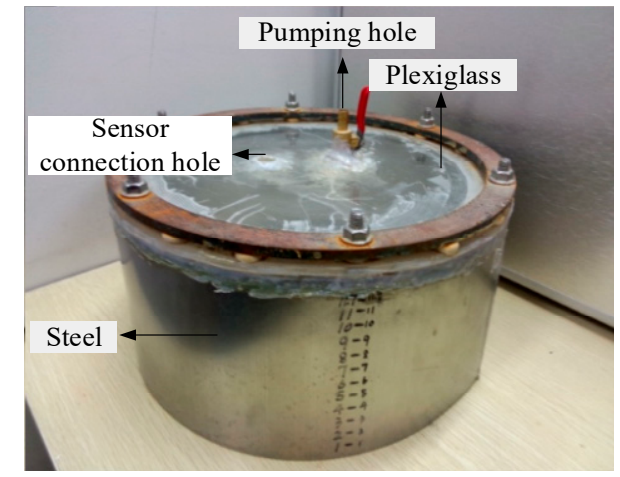

(a)

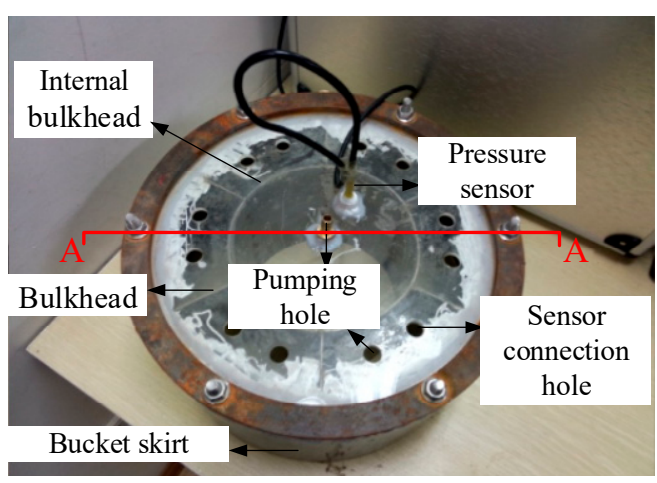

(c)

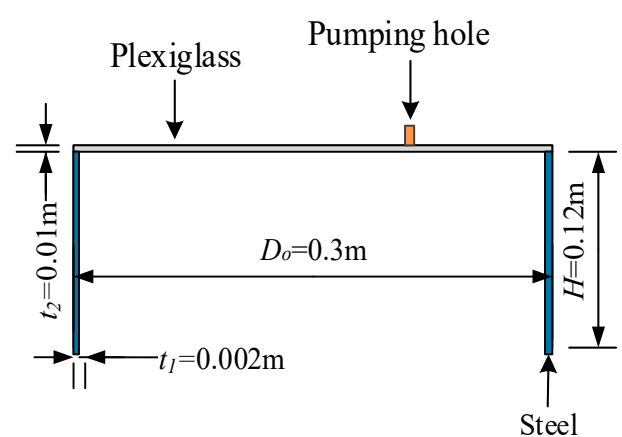

(b)

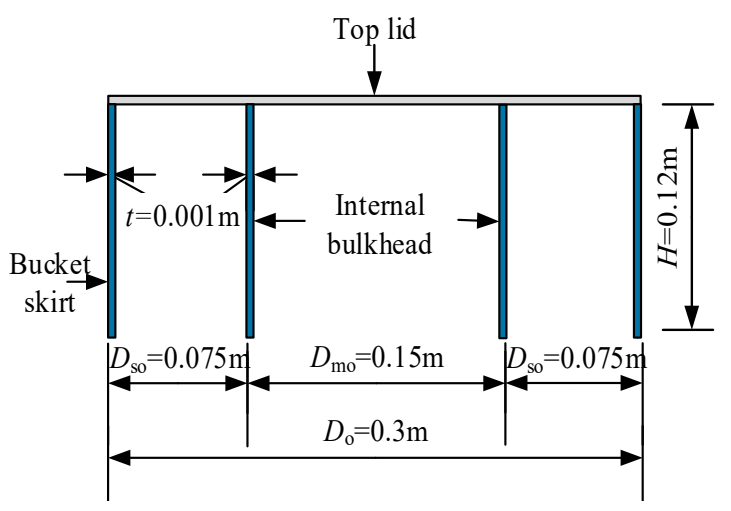

(d)

Figure 2. Schematic diagram of test model in sand. (a) Mono-compartment bucket foundation model; (b) Schematic diagram of the mono-compartment bucket foundation; (c) Mono-bucket multi-compartment foundation model; (d) Schematic diagram of the mono-bucket multi-compartment foundation.

Figure 3 shows the sand penetration test system, whose pumping system provides suction for the multi-compartment bucket foundation and guarantees the stability of negative pressure applied in each stage. 


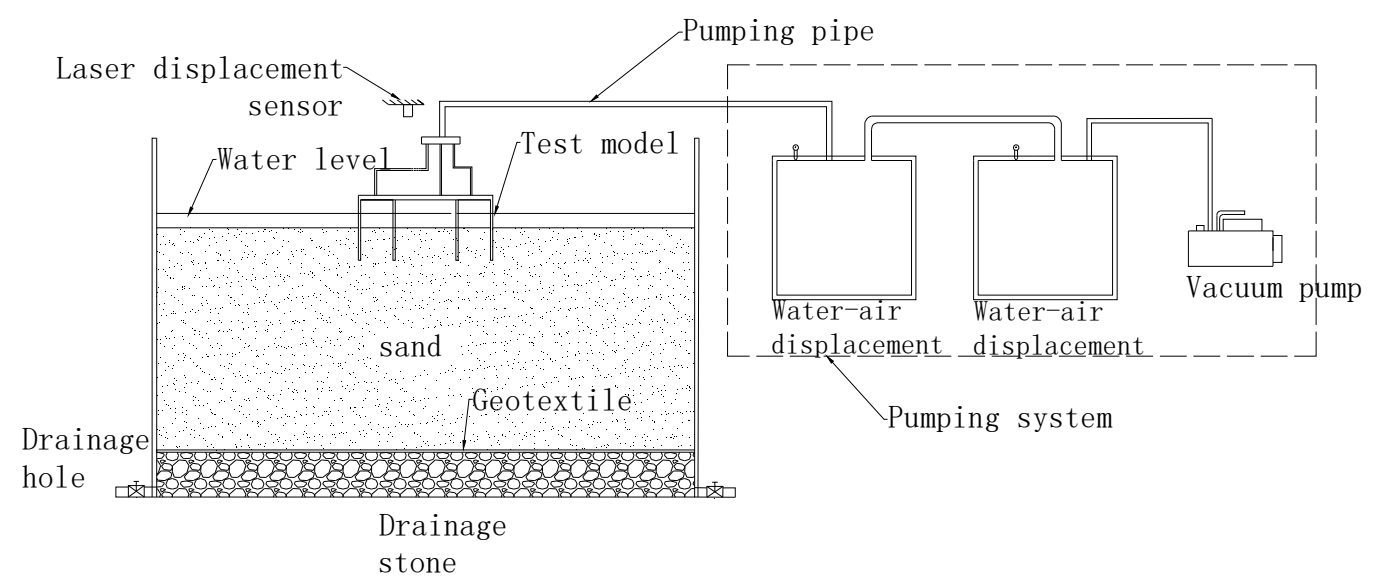

Figure 3. Schematic diagram of the test.

\subsection{Sand Preparation}

The sand used in this test was collected from the Bohai Bay, Tianjin. Figure 4 shows the particle size distribution curve of sand obtained using the laboratory soil test, and Table 2 lists the physical and mechanical parameters of the sand. The sand had a coefficient of non-uniformity of $C_{u}=2.9$. According to the sand classification criteria, the content of the grains with a diameter of greater than $0.25 \mathrm{~mm}$ did not exceed $50 \%$ of total weight, and the content of grains with a diameter greater than $0.075 \mathrm{~mm}$ exceeded $85 \%$. Fine sand was used in this test and, after the completion of the test under each working condition, the sand was vibrated to guarantee the same density.

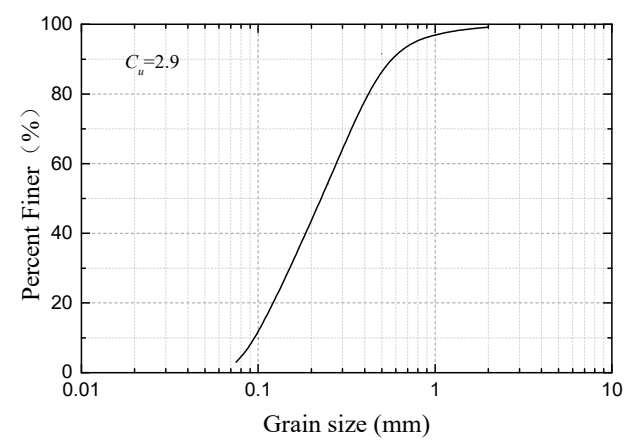

Figure 4. Particle size distribution curve.

Table 2. Physical and mechanical properties of soil.

\begin{tabular}{ccccccc}
\hline Texture & $\begin{array}{c}\text { Water } \\
\text { Content } w \mathbf{( \% )}\end{array}$ & $\begin{array}{c}\text { Density } \\
\left(\mathrm{g} / \mathbf{c m}^{\mathbf{3}}\right)\end{array}$ & $\begin{array}{c}\text { Frictional } \\
\text { Angle } \boldsymbol{\varphi}\end{array}$ & $\begin{array}{c}\text { Relative } \\
\text { Density }\end{array}$ & $\begin{array}{c}\text { Permeability } \\
\text { Coefficient } \boldsymbol{k}(\mathbf{m} / \mathbf{s})\end{array}$ & Void Ratio $\boldsymbol{e}$ \\
\hline Fine sand & 21.5 & 2.18 & 34.16 & 0.779 & $1.425 \times 10^{-6}$ & 0.479 \\
\hline
\end{tabular}

\subsection{Test Process and Test Conditions}

The penetration of the mono-compartment/multi-compartment bucket foundation comprises two stages. In the first stage, the vent holes on the head cover were opened, and the model penetrated stably under self-weight. In the second stage, the vacuum pump and the water-air displacements were loaded in steps, i.e., stepwise penetration: first, the valve between the foundation and the water-air displacements were closed, and the air in the water-air displacement was pumped out using a vacuum pump, so that the suction pressure of the water-air displacement would reach the preset level. After that, the valve of the water-air displacement connected to the model was gradually opened to slowly form a steady negative pressure inside the foundation. When the model began to penetrate 
stably under a stable suction, the pipeline regulation valve was closed, after which the suction soon disappeared. Following that, the above steps were repeated to apply stable suction for the next stage until the model penetrated in place. The test adopted three-step negative pressure loading and six-step negative pressure loading, and ultimately penetrated to a depth equal to the bucket height. In the test process, the angle of inclination of the foundation was controlled to a maximum of $0.17^{\circ}$ which can be monitored by the inclinometer, and this angle is used in the industrial project. Figure 5 shows the layout of the sensors in the test, and Table 3 lists the test conditions of this study.

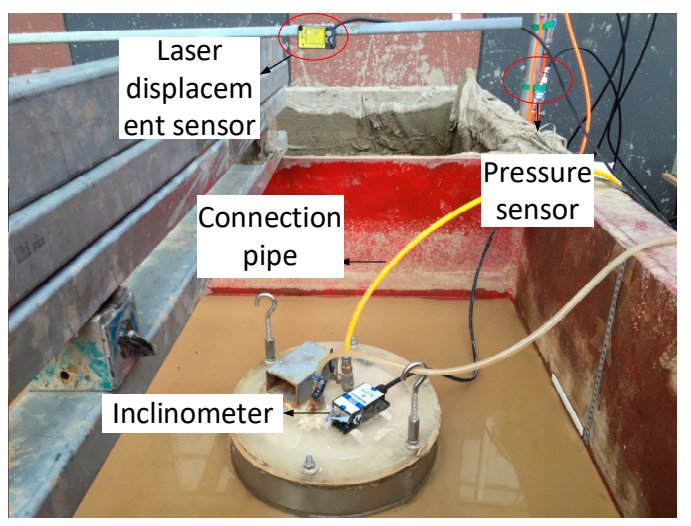

(a)

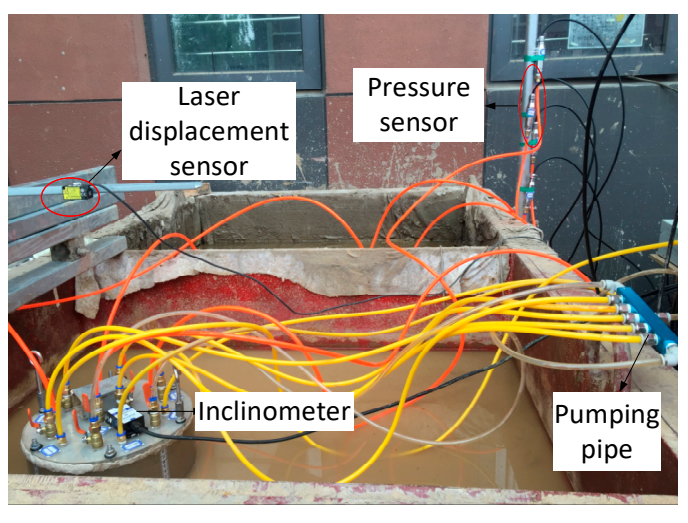

(b)

Figure 5. Layout of sensors. (a) mono-compartment bucket foundation; (b) multi-compartment bucket foundation.

Table 3. Contents of penetration test in sand.

\begin{tabular}{cc}
\hline Test Number & Foundation Type \\
\hline PS1-1 & Mono-compartment bucket foundation \\
PS1-2 & \\
PS2-1 & Multi-compartment bucket foundation \\
PS2-2 & \\
\hline
\end{tabular}

\section{Test Results}

\subsection{Effect of the Mode of Suction Application on Penetration Resistance}

Figures 6 and 7 show the variation curves of suction and displacement with time in the penetration process of the mono-compartment bucket foundation. The water level on the saturated sand was low. In foundation penetration, there was air in the bucket, so pumping out the air would create a negative pressure inside. In that case, suction was the pressure difference inside and outside the bucket, and the sum of the suction and foundation self-weight was the driving force required by foundation penetration. Regarding the relationship curve between the displacement and time, the $\mathrm{x}$-coordinate denotes the time of suction penetration, while the $\mathrm{y}$-coordinate denotes the penetration displacement of the foundation. The curve only illustrates the suction penetration process. Given that the foundation penetrated to $15 \mathrm{~mm}$ under self-weight, suction penetration had an initial displacement of $15 \mathrm{~mm}$. As shown in Figures 8 and 9, PS1-1 and PS1-2 adopted three-step and six-step loading, respectively, and penetration suction increased stepwise. The suction of each step was maintained at a relatively stable state until the displacement of the foundation would no longer increase. After that, suction was increased to carry on foundation penetration. Ultimately, the foundation penetrated to approximately $-110 \mathrm{~mm}$, and the final suction required by penetration was uniformly approximately $-2.5 \mathrm{kPa}$. 


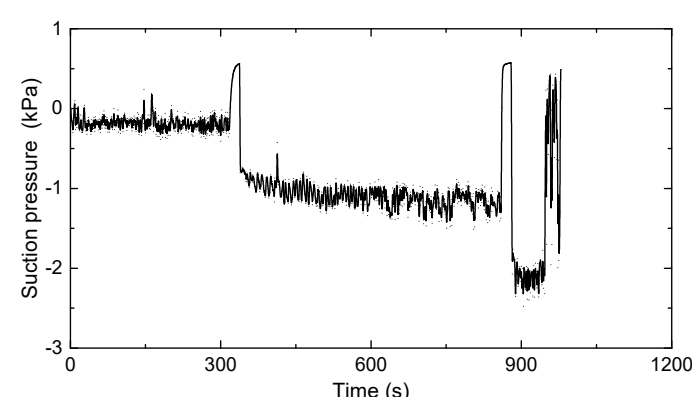

(a)

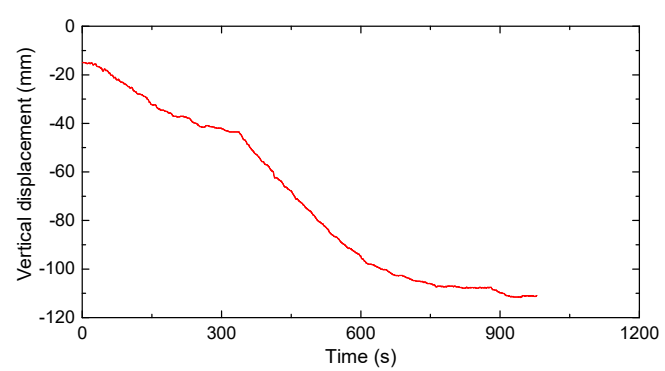

(b)

Figure 6. Variations in suction and displacement with time in PS1-1. (a) Relationship between suction and time; (b) Relation between displacement and time.

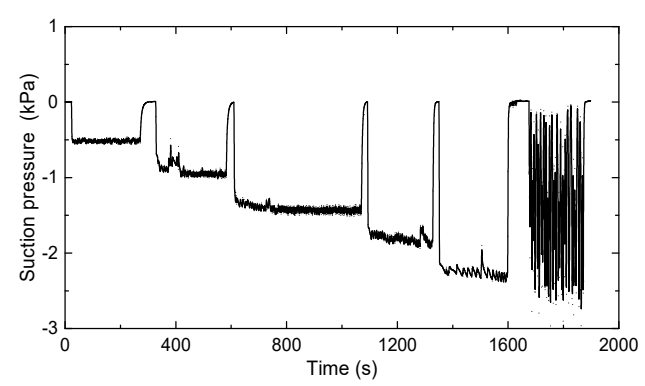

(a)

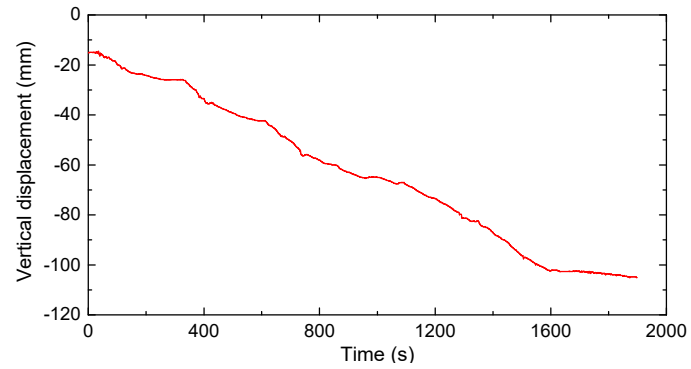

(b)

Figure 7. Variations in suction and displacement with time in PS1-2. (a) Relationship between suction and time; (b) Relationship between displacement and time.

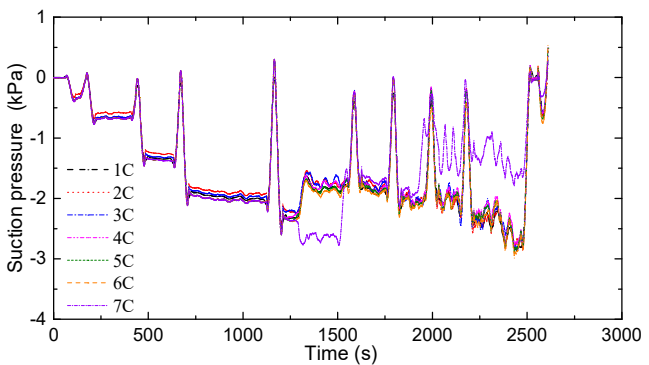

(a)

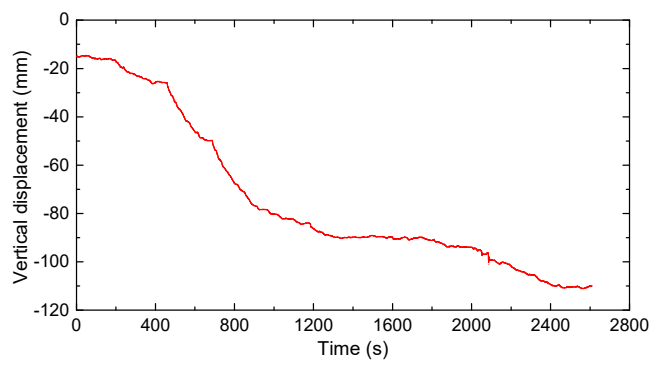

(b)

Figure 8. Variations in suction and displacement with time in PS2-1. (a) Relationship between suction and time; (b) Relationship between displacement and time.

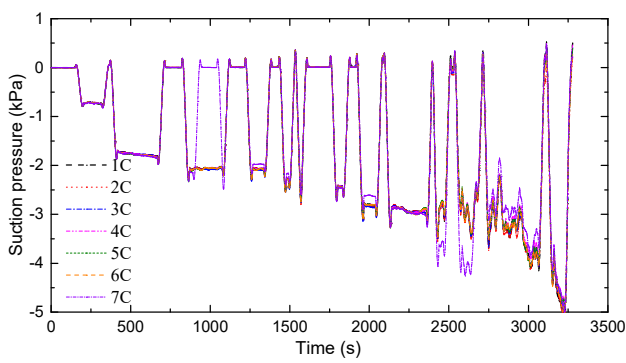

(a)

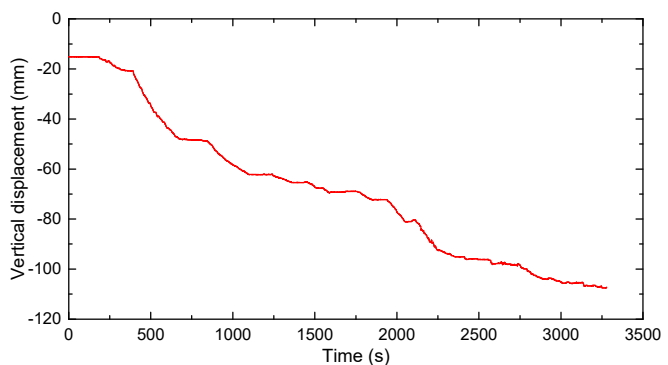

(b)

Figure 9. Variations in suction and displacement with time in PS2-2. (a) Relationship between suction and time; (b) Relationship between displacement and time. 
Figures 8 and 9 show the variation curves of suction and displacement with time in the penetration process of the multi-compartment bucket foundation, where the x-coordinate denotes the time of penetration, while the y-coordinate denotes suction or displacement. The seven curves shown in Figures $8 \mathrm{a}$ and $9 \mathrm{a}$ denote the internal pressures of the seven compartments, and the curve named 1C means the No.1 compartment of the multi-compartment bucket foundation. The consistency in the variations of the seven curves suggests that all the compartments in the bucket had the same suction. Neither Figure 8b nor Figure 9b contain the self-weight penetration process of the foundation. With increasing suction applied to a foundation, the penetration depth of the foundation increased as well. Ultimately the foundation penetrated to approximately $-110 \mathrm{~mm}$, in which case the internal pressure of the compartment was roughly $-4 \mathrm{kPa}$.

As indicated by a comparison between the mono-compartment and multi-compartment bucket foundations in terms of their penetration processes, the penetration methods uniformly adopted stepwise loading, with small penetration suction in each case. Ultimately, they had the same penetration depth, with the same soil plug height of $10 \mathrm{~mm}$, as shown in Figure 10. In the end, neither of them could fully penetrate into the soil. In the case of the mono-compartment bucket foundation the soil plug heights were consistent, and the soil plug heights in the middle and on the sides of the bucket were almost the same. In the case of the multi-compartment bucket foundation, the side compartments and the central compartment had different soil plug heights. The side compartments underwent more serious soil plug and had a larger soil plug height than that of the central compartment, probably because of the two reasons. First, the side compartments had a smaller cross-sectional area and soil dilatancy is more obvious. Second, under the action of penetration suction, the sand at the bottom of the bucket wall had a larger hydraulic gradient, and the sand would flow across the bucket wall into the bucket.

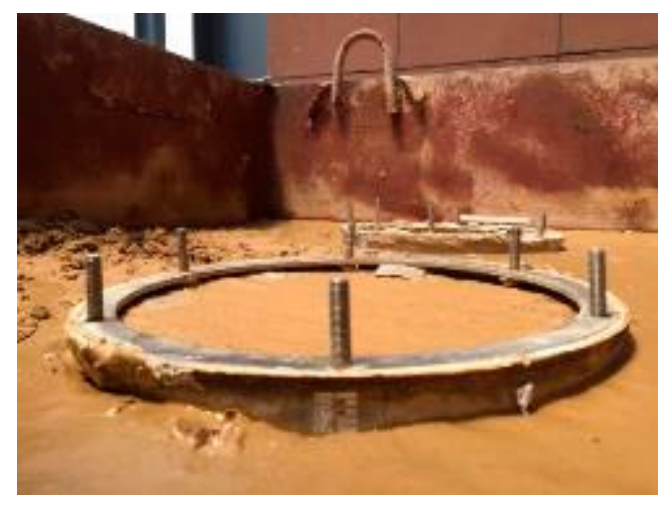

(a)

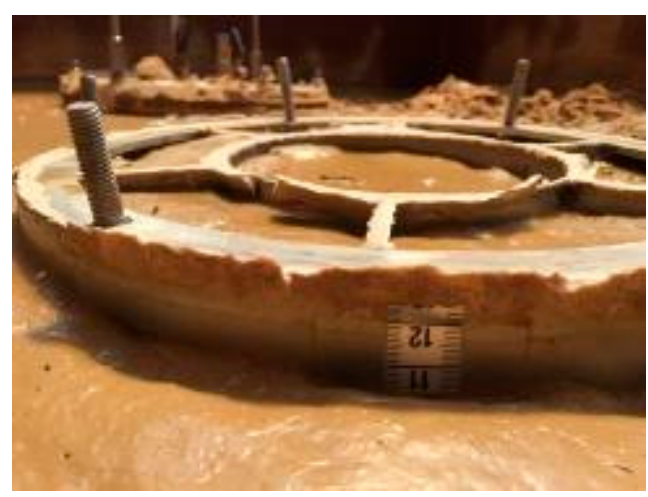

(b)

Figure 10. Soil plug in the penetration of the bucket foundation. (a) Mono-compartment bucket foundation; (b) Multi-compartment bucket foundation.

\subsection{Effects of Inner Skirt Plates and Bulkheads on Penetration Resistance}

The penetration resistance of the mono-compartment and multi-compartment bucket foundations were compared under the same texture condition to analyze the effects of inner skirt plates and bulkheads on the penetration resistance of foundations. To prevent analysis results from being affected by the foundation dimensions, analysis variables were nondimensionalized.

Figure 11 compares the relationship curves between the penetration depth and applied suction for the mono-compartment and multi-compartment bucket foundations, where the transverse axis denotes dimensionless suction, and the longitudinal axis denotes dimensionless penetration depth. In Figure 11, $\mathrm{h}$ is the penetration depth of the foundation, $D$ is the inner diameter of the bucket, $D_{0}$ is the outer diameter, $D=\left(D_{i}+D_{o}\right) / 2 ; \gamma^{\prime}$ is the effective unit weight of sand, and $s$ is the penetration suction is denoted by s. Apparently, the penetration suction of the mono-compartment bucket foundation was smaller than that of the mono-bucket multi-compartment foundation. 


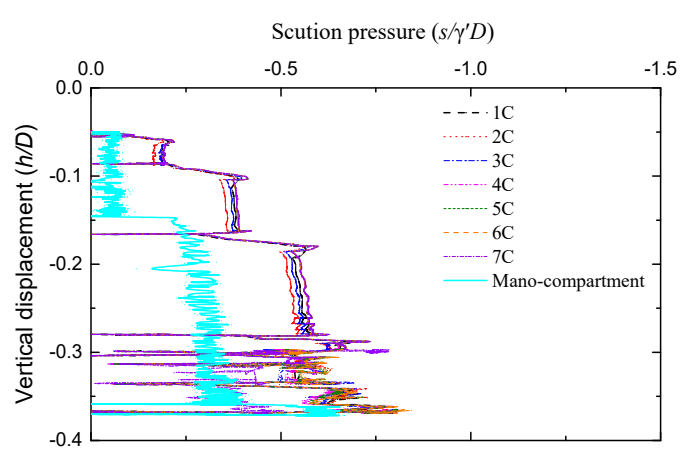

(a)

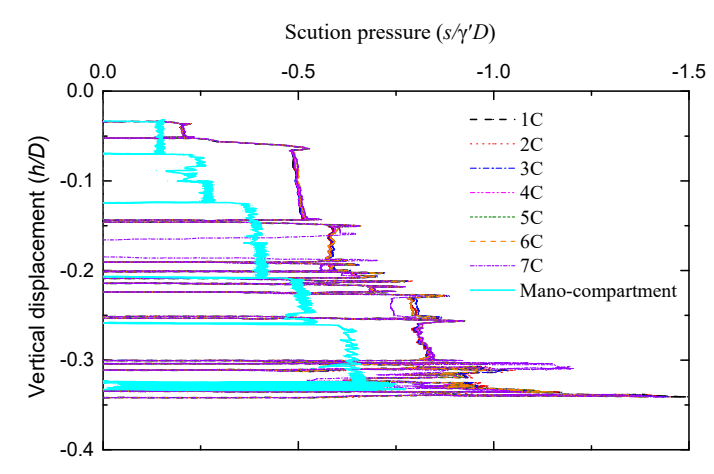

(b)

Figure 11. Relationship curve between the penetration depth and applied suction for mono-compartment and multi-compartment bucket foundations. (a) PS1-1 and PS2-1; (b) PS1-2 and PS2-2.

The penetration resistance of a foundation is the sum of the penetration suction and the self-weight of the foundation. In this study, the penetration resistances of the mono-compartment and multi-compartment bucket foundations were calculated and nondimensionalized, thus acquiring the penetration resistance differences between the two foundations at different penetration depths, as shown in Figure 12. Figure 12a shows the penetration resistances of PS1-1 and PS2-1 and their penetration resistance difference; Figure 12b shows the penetration resistances of PS1-2 and PS2-2 and their penetration resistance difference. In Figure 12, the transverse axis denotes the dimensionless penetration resistance (where $A_{\text {cross }}$ is the cross-sectional area of the bucket foundation), while the longitudinal axis denotes the ratio of the penetration depth to the foundation diameter.

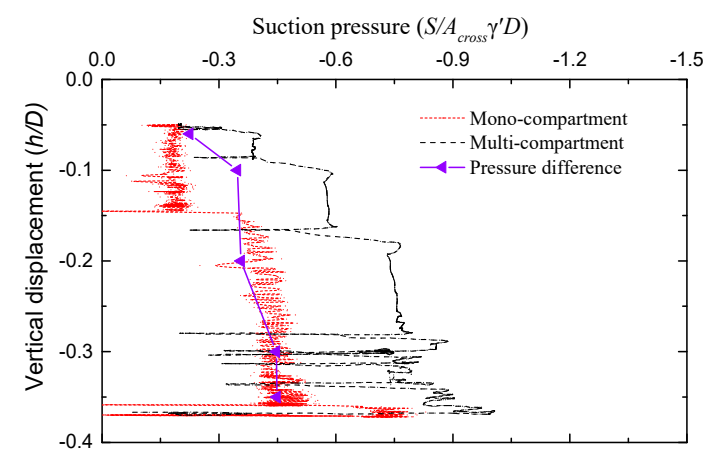

(a)

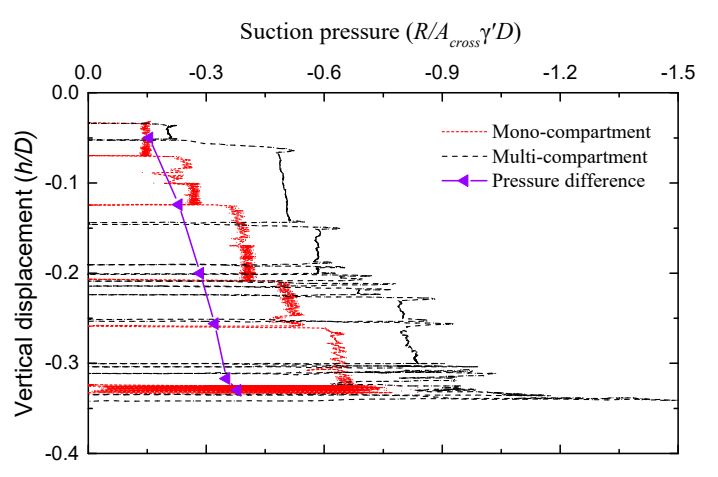

(b)

Figure 12. Effects of inner skirt plates and bulkheads on penetration resistance. (a) PS1-1 and PS2-1; (b) PS1-2 and PS2-2.

As shown in Figure 12, the penetration resistance of the mono-compartment bucket foundation was less than that of the multi-compartment bucket foundation. In the initial stage of suction penetration, the penetration resistance difference between the two foundations was small-with increasing penetration depth, it increased as well. The reason for this was that, in the initial stage of foundation penetration, the penetration depth was small, and the side frictions of the inner skirt plates and bulkheads were low, resulting in a small penetration resistance difference between the two foundations. However, with increasing penetration depth, the side frictions of the inner skirt plates and bulkheads gradually increased as well, further enlarging the penetration resistance difference. 


\subsection{Critical Suction in the Penetration Process of the Bucket Foundation in Sand}

3.3.1. Verification of the Critical Suction in the Penetration Process of the Mono-Compartment Bucket Foundation

At present, there are already some mature models for calculating the critical suction in the penetration process of the traditional mono-compartment bucket foundation. Thus, the first step is to deduce a model for calculating the critical suction of the mono-compartment bucket foundation and then compare it with the existing calculation models [26].

The relationship between the hydraulic gradient $i$, suction $s$, and seepage path $l$ can be expressed as follows:

$$
i=\frac{s}{\gamma_{w} l}
$$

When hydraulic gradient $i$ reaches the following critical gradient, sand experiences seepage failure, in which case the critical suction $s_{\text {rcit }}$ is represented by the following formula.

$$
\begin{gathered}
i_{r c i t}=\frac{\gamma^{\prime}}{\gamma_{w}} \\
s_{r c i t}=l \gamma_{w} i_{c r i t}
\end{gathered}
$$

The site experiencing seepage failure first was the mud surface on the inner side of bucket wall, i.e., the hydraulic outlet adjoining the bucket wall. The above formula was used to deduce the dimensionless relationship between the seepage path and penetration depth, as shown in Figure 13. Next, the seepage path obtained can be substituted into Formula (3) to acquire the relationship between the critical suction and penetration depth, as shown in Figure 14.

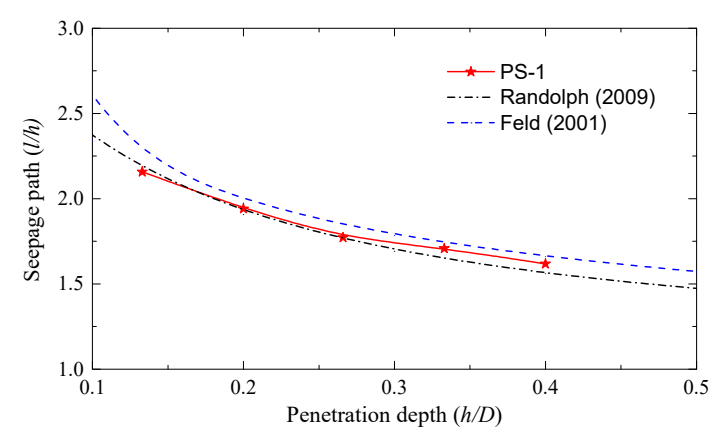

Figure 13. Relationship between the seepage path and penetration depth.

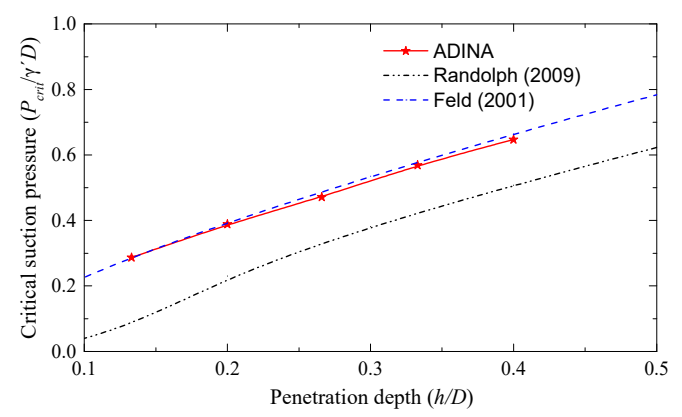

Figure 14. Relationship between the critical suction and penetration depth.

This study mainly focused on the wide-shallow bucket foundations; therefore, the range of $h / D$ was confined to $0-0.4$ in this study. The results of the seepage path and critical suction calculated in this study were compared to the values calculated by Randolph and Feld's formulas [25,26]. As shown 
in Figure 13, the seepage paths obtained by the three methods were very close. In Figure 14, the critical suction calculated in this study fitted well with the value calculated by Randolph's formula [25].

\subsubsection{Critical Suction in the Penetration Process of the Multi-Compartment Bucket Foundation}

The seepage path and critical suction for the multi-compartment bucket foundation were calculated by the same method as used for the mono-compartment bucket foundation. Due to the use of inner skirt plates and bulkheads, the multi-compartment bucket foundation had three hydraulic outlets, i.e., $G, F$, and $H$, as shown in Figure 15. Each of the above three outlets was in turn taken as the point experiencing seepage failure first to calculate the seepage path and critical suction, as shown in Figures 15 and 16. The result indicates that the hydraulic outlet $G$ had the shortest seepage path and the smallest critical suction. As a result, with increasing penetration suction, point $G$ would be most susceptible to seepage failure; therefore, the critical suction at hydraulic outlet $G$ should be adopted as the control criterion on the maximum suction for mono-bucket multi-compartment foundation. Through curve fitting based on these points, the dimensionless functional relationship between the critical suction and penetration depth was obtained, as shown by Equation (4):

$$
\frac{p_{c r}}{\gamma^{\prime} D}=1.82\left(\frac{h}{D}\right)^{0.81}
$$

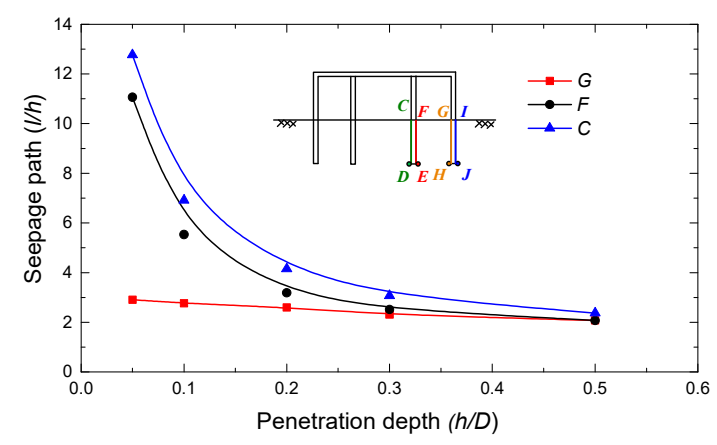

Figure 15. Relationship between the seepage path and penetration depth.

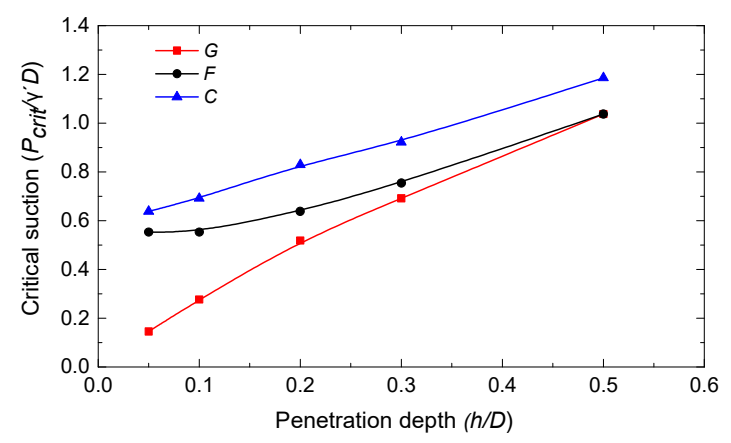

Figure 16. Relationship between the critical suction and penetration depth.

The critical suction calculated by the formula and the suction actually applied in the test was compared, as shown in Figure 17. Clearly, the suction actually applied in the test was always less than the critical suction, except in the initial stage of PS2-2 (where it was greater than the critical suction due to improper suction control). No seepage failure occurred in the test process, and this result was consistent with our observation. 


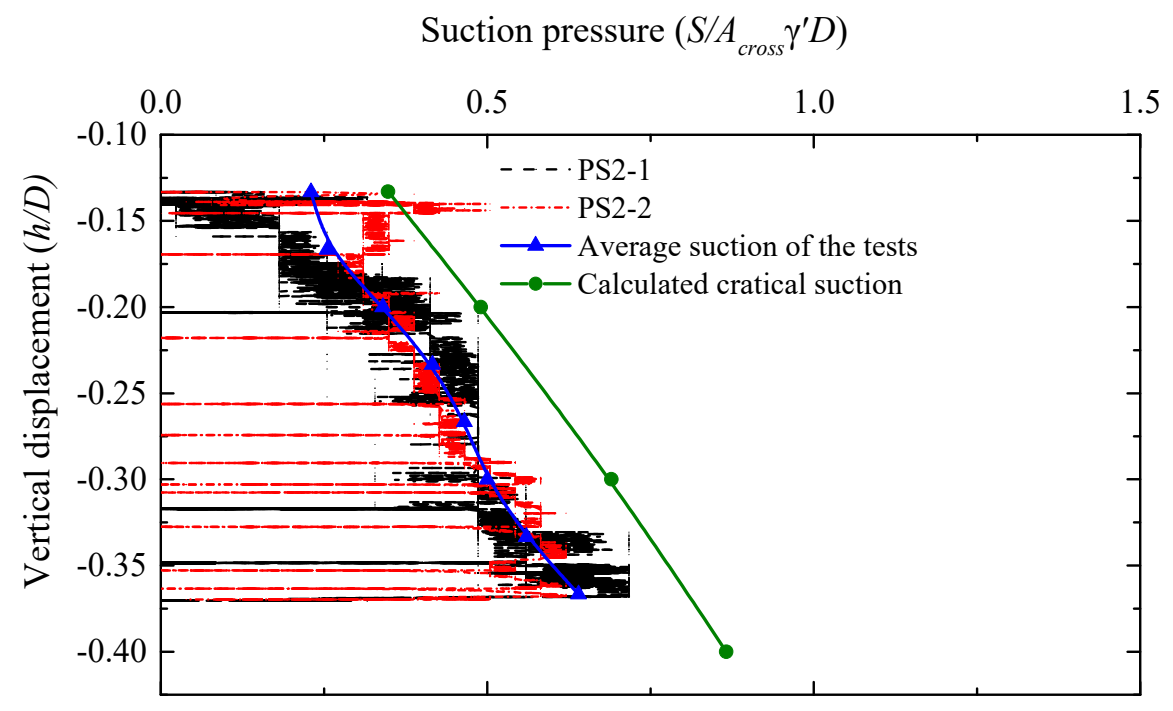

Figure 17. Comparison between the calculated critical suction and measured suction.

\section{Conclusions}

In conclusion, a model test was designed and successfully applied to the suction penetration of a mono-compartment bucket foundation and a multi-compartment bucket foundation in sand to investigate the effects of inner skirt plates and bulkheads on the penetration resistance of the multi-compartment bucket foundation. The test results indicate that the penetration resistance of the mono-compartment bucket foundation was clearly less than that of the mono-bucket multi-compartment foundation. In the initial stage of the suction penetration, the penetration resistance difference between the two foundations was small. Later, the increase in the penetration depth increased the penetration resistance difference.

In the penetration process, both of them experienced soil plug. Specifically, the mono-compartment bucket foundation exhibited consistent soil plug heights. The multi-compartment bucket foundation had different soil plug heights on the side compartments and the central compartment.

The side compartments underwent more serious soil plug and had a larger soil plug height than that of the central compartment. In addition, in the course of foundation penetration, the soil surface on the inner side of the bucket wall was the hydraulic outlet most susceptible to seepage failure, or the site experiencing seepage failure first. Taking this as the criterion for judging the occurrence of sand seepage failure, the critical suction in the penetration process of the multi-compartment bucket foundation was analyzed.

Author Contributions: Conceptualization, H.D. and P.Z.; methodology, Y.P. and N.J.; software, Y.P.; validation, N.J. and H.Z.; formal analysis, Y.P. and H.Z.; investigation, P.Z. and N.J.; resources, N.J. and H.D.; data curation, N.J.; writing — original draft preparation, Y.P. and N.J.; writing-review and editing, P.Z. and H.Z.; funding acquisition, H.D. and P.Z. All authors have read and agreed to the published version of the manuscript.

Funding: This research was funded by the National Natural Science Foundation of China (Grant Nos. 51679163 \& 51779171).

Conflicts of Interest: The authors declare no conflict of interest.

\section{References}

1. Zhang, L.X.; Shi, W.; Karimirad, M.; Michailides, C.; Jiang, Z. Second-order hydrodynamic effects on the response of three semisubmersible floating offshore wind turbine. Ocean Eng. 2020, 207, 107371. [CrossRef]

2. Tang, Y.; Shi, W.; You, J.K.; Michailides, C. Effects of nonlinear wave loads on large monopile offshore wind turbines with and without ice-breaking cone configuration. J. Mar. Sci. Technol. 2020, 1-17. [CrossRef] 
3. Fu, D.F.; Zhang, Y.H.; Yan, Y.; Jostad, H.P. Effects of tension gap on the holding capacity of suction anchors. Mar. Struct. 2020, 69, 102679. [CrossRef]

4. Wang, X.F.; Zeng, X.; Li, J. Vertical performance of suction bucket foundation for offshore wind turbines in sand. Ocean Eng. 2019, 180, 40-48. [CrossRef]

5. Tjelta, T.I. Geotechnical experience from installation of the Europipe jacket with bucket foundation. In Proceedings of the Offshore Technology Conference OTC7795, Houston, TX, USA, 1-4 May 1995; pp. 897-908.

6. Houlsby, G.T.; Ibsen, L.B.; Byrne, B.W. Suction caissons for wind turbines. In Frontiers in Offshore Geotechnics; ISFOG-Gourvenec \& Cassidy , Ed.; Taylor \& Francis Group: London, UK, 2005; pp. 75-93. ISBN 0 41539063X.

7. LeBlanc, C. Design of Offshore Wind Turbine Support Structures. Ph.D. Thesis, Aalborg University, Aalborg, Denmark, 2009.

8. Villalobos, F.A. Model Testing of Foundations for Offshore Wind Turbines. Ph.D. Thesis, University of Oxford, Oxford, UK, 2006.

9. Ding, H.Y.; Lian, J.J.; Li, A.D.; Zhang, P.Y. One-step-installation of offshore wind turbine on large-scale bucket-top-bearing bucket foundation. Trans. Tianjin Univ. 2013, 19, 188-194. [CrossRef]

10. Zhang, P.Y.; Ding, H.Y.; Le, C.H. Motion analysis on integrated transportation technique for offshore wind turbines. J. Renew. Sustain. Energy 2013, 5, 053117. [CrossRef]

11. Ding, H.Y.; Liu, Y.G.; Le, C.H.; Zhang, P.Y. Model tests on the bearing capacity of wide-shallow composite bucket foundations for offshore wind turbines in clay. Ocean Eng. 2015, 103, 114-122. [CrossRef]

12. Zhang, P.Y.; Ding, H.Y.; Le, C.H. Seismic response of large-scale prestressed concrete bucket foundation for offshore wind turbines. J. Renew. Sustain. Energy 2014, 6, 13127. [CrossRef]

13. Zhang, P.Y.; Ding, H.Y.; Le, C.H. Hydrodynamic motion of a large prestressed concrete bucket foundation for offshore wind turbines. J. Renew. Sustain. Energy 2013, 5, 063126. [CrossRef]

14. Ding, H.Y.; Hu, R.Q.; Zhang, P.Y.; Le, C.H. Load bearing behaviors of composite bucket foundations for offshore wind turbines on layered soil under combined loading. Ocean Eng. 2020, 198, 106997. [CrossRef]

15. Clausen, C.J.F.; Tjelta, T.I. Offshore platforms supported by bucket foundations. In Proceedings of the 15th IABSE, Copenhagen, Denmark, 16-20 June 1996; pp. 819-829.

16. Sahota, B.; Wilson, Q. The breakout behavior of a suction anchor embedded in submerged sand. In Proceedings of the Offshore Technology Conference, Houston, TX, USA, 3-6 May 1982; pp. 117-132.

17. Barari, A.; Ibsen, L.B. Undrained response of bucket foundations to moment loading. Appl. Ocean Res. 2012, 36, 12-21. [CrossRef]

18. Villalobos, F.A.; Byrne, B.W.; Houlsby, G.T. Model testing of suction caissons in clay subjected to vertical loading. Appl. Ocean Res. 2010, 32, 414-424. [CrossRef]

19. Achmus, M.; Akdag, C.T.; Thieken, K. Load-bearing behavior of suction bucket foundations in sand. Appl. Ocean Res. 2013, 43, 157-165. [CrossRef]

20. Ibseb, L.B.; Thilsted, C.L. Numerical study of piping limits for suction installation of offshore skirted foundations and anchors in layered sand. In Proceedings of the International Symposium on Frontiers in Offshore, Perth, Australia, 8-10 November 2010.

21. Erbrich, C.T.; Tjelta, T.I. Installation of bucket foundations and suction caissons in sand-geotechnical performance. In Proceedings of the Offshore Technology Conference, Houston, TX, USA, 3-6 May 1999.

22. Guo, Z.; Wang, L.Z.; Yuan, F.; Li, L.L. Model tests on installation techniques of suction caissons in a soft clay seabed. Appl. Ocean Res. 2012, 34, 116-125. [CrossRef]

23. Harireche, O.; Mehravar, M.; Alani, A.M. Soil conditions and bounds to suction during the installation of caisson foundations in sand. Ocean Eng. 2014, 88, 164-173. [CrossRef]

24. Tran, M.N.; Randolph, M.F.; Airey, D.W. Study of sand heave formation in suction caissons using Particle Image Velocimetry(PIV). In Proceedings of the 1st International Symposium on Frontiers in Offshore Geotechnics, Perth, Australia, 19-21 September 2005; pp. 259-265.

25. Senders, M.; Randolph, M.F. CPT-based method for the installation of suction caissons in sand. J. Geotech. Geoenvironmental Eng. 2009, 135, 14-25. [CrossRef]

26. Feld, T. Suction Buckets, A New Innovative Foundation Concept, Applied to Offshore Wind Turbines. Ph.D. Thesis, Aalborg University, Aalborg, Denmark, 2001.

27. Zhang, P.Y.; Guo, Y.H.; Liu, Y.G.; Ding, H.Y.; Le, C.H. Model tests on sinking technique of composite bucket foundations for offshore wind turbines in silty clay. Renew. Sustain. 2015, 7, 033113. [CrossRef] 
28. Zhang, P.Y.; Guo, Y.H.; Liu, Y.G.; Ding, H.Y. Experimental study on installation of hybrid bucket foundations for offshore wind turbines in silty clay. Ocean Eng. 2016, 114, 87-100. [CrossRef]

29. Zhang, P.Y.; Han, Y.Q.; Ding, H.Y.; Zhang, S.Y. Field experiments on wet tows of an integrated transportation and installation vessel with two bucket foundations for offshore wind turbines. Ocean Eng. 2015, 108, 769-777. [CrossRef]

30. Zhang, P.Y.; Zhang, Z.; Liu, Y.G.; Ding, H.Y. Experimental study on installation of composite bucket foundations for offshore wind turbines in silty sand. Offshore Mech. Arctic Eng. 2016, 138, 061901.

(C) 2020 by the authors. Licensee MDPI, Basel, Switzerland. This article is an open access article distributed under the terms and conditions of the Creative Commons Attribution (CC BY) license (http://creativecommons.org/licenses/by/4.0/). 